06.1

\title{
Повышение эффективности и длительности эмиссии углеродных нанотрубок после обработки в плазме аммиака
}

\author{
(C) С.В. Булярский ${ }^{1,2}$, В.С. Белов ${ }^{1,3}$, Е.П. Кицюк ${ }^{2}$, А.В. Лакалин ${ }^{1}$, М.С. Молоденский ${ }^{1}$, А.А. Павлов ${ }^{1}$, \\ Р.М. Рязанов ${ }^{2}$, А.В. Терентьев ${ }^{1}$, А.А. Шаманаев ${ }^{2}$ \\ ${ }^{1}$ Институт нанотехнологий микроэлектроники РАН, Москва, Россия \\ ${ }^{2}$ НПК „Технологический центр“, Москва, Россия \\ ${ }^{3}$ Национальный исследовательский университет „МИЭТ“, Москва, Россия \\ E-mail: bulyar2954@mail.ru
}

Поступило в Редакцию 30 декабря 2019 г.

В окончательной редакции 10 июля 2020 г.

Принято к публикации 15 июля 2020 г.

Разработана технология легирования углеродных нанотрубок азотом в плазме аммиака. Нанотрубки, синтезированные по технологии, исключающей легирование азотом, подвергались обработке в плазме аммиака. В результате концентрация азота в нанотрубках увеличивалась в 5 раз с 0.7 до 3.6 at.\%, сопротивление нанотрубок падало в 6 раз, работа выхода уменьшалась на $10 \%$. Такое воздействие приводило к стабилизации процесса эмиссии.

Ключевые слова: углеродные нанотрубки, легирование азотом, плазма аммиака, холодная эмиссия.

DOI: 10.21883/PJTF.2020.20.50146.18172

Углеродные нанотрубки (УНТ) обладают рядом уникальных свойств, которые стимулируют их использование в наноэлектронике. Наиболее часто они применяются в качестве канала полевых транзисторов [1] и катодов холодных эмиттеров [2-4]. УНТ необходимо легировать в обоих случаях. В настоящее время легирование нанотрубок осуществляется в процессе синтеза [5,6], однако управляемые технологии создания наноэлектронных приборов требуют поиска путей управления свойствами нанотрубок и после синтеза. Обработка УНТ, применяемых для создания холодных катодов, преследует две основные цели: уменьшение работы выхода электрона из катода и снижение последовательного сопротивления тела катода. Важным фактором повышения эффективности эмиссии является снижение работы выхода. В этом направлении ведутся теоретические [7,8] и прикладные исследования [9-14]. В работе [8] были изучены 12 различных металлических адатомов на графене методами теории функционала плотности и были сделаны оценки изменения работы выхода. На практике для этого наносят слои окислов меди [9] или цинка [10]. Как и в случае фотокатодов, нанесение слоев цезия является эффективным методом снижения работы выхода [11-14]. Цезий позволяет снизить работу выхода из нанотрубок с 4.8 до $3.8 \mathrm{eV}$. Еще более эффективным технологическим приемом является обработка готовых холодных эмиттеров в плазме водорода, которая понижает работу выхода углеродной нанотрубки с 4.8 до $3.3 \mathrm{eV}$ [15].

Снижение сопротивления углеродной нанотрубки уменьшает в ней выделение тепла и перегрев ее конца, испускающего электроны, который может быть значительным $[4,16]$. Такой перегрев приводит к возникновению явления термоэлектронной эмиссии и разрушению конца трубки, что ведет к деградации катода в целом. Легирование азотом приводит к донорному эффекту и увеличивает электронную проводимость трубки [5,17-20], что должно снижать сопротивление нанотрубки и приводить к стабилизации эмиссии. В связи с этим в настоящей работе исследуется влияние обработки в плазме аммиака на эмиссионные структуры на основе углеродных нанотрубок. Результаты работы показывают, что данный технологический процесс существенно снижает последовательное сопротивление нанотрубок и стабилизирует эмиссию во времени.

В качестве исходных подложек использовался монокристаллический кремний марки КЭМ ориентации (100) с удельным сопротивлением $0.003-0.005 \Omega \cdot \mathrm{cm}$. На подложки напылялись каталитический слой (диффузионнобарьерный Ті толщиной $25 \mathrm{~nm})$ и собственно катализатор синтеза УНТ (Ni толщиной $5 \mathrm{~nm}$ ). Синтез массивов углеродных нанотрубок проводился методом плазмостимулированного химического парофазного осаждения. В едином цикле осуществлялись окислительный и восстановительный отжиг, требуемые для формирования наночастиц катализатора из тонких пленок, а также непосредственно синтез. Окислительный отжиг длительностью $10 \mathrm{~min}$ проходил в потоке аргона $\left(300 \mathrm{~cm}^{3} / \mathrm{min}\right)$ и кислорода $\left(100 \mathrm{~cm}^{3} / \mathrm{min}\right)$ при температуре $280^{\circ} \mathrm{C}$ при включении высокочастотной плазмы мощностью $100 \mathrm{~W}$. Восстановительный отжиг осуществлялся в потоке аргона $\left(300 \mathrm{~cm}^{3} / \mathrm{min}\right)$ и аммиака $\left(100 \mathrm{~cm}^{3} / \mathrm{min}\right)$ в течение $10 \mathrm{~min}$ при температуре $680^{\circ} \mathrm{C}$ и той же мощности плазмы. Синтез проводился при температуре $680^{\circ} \mathrm{C}$ в течение 5 min при давлении 2 Torr в потоке газов: $\mathrm{H}_{2}-$ $100 \mathrm{~cm}^{3} / \mathrm{min}, \mathrm{Ar}-100 \mathrm{~cm}^{3} / \mathrm{min}, \mathrm{C}_{2} \mathrm{H}_{2}-100 \mathrm{~cm}^{3} / \mathrm{min}$. $\mathrm{B}$ процессе синтеза мощности плазмы составляли $20 \mathrm{~W}$ 

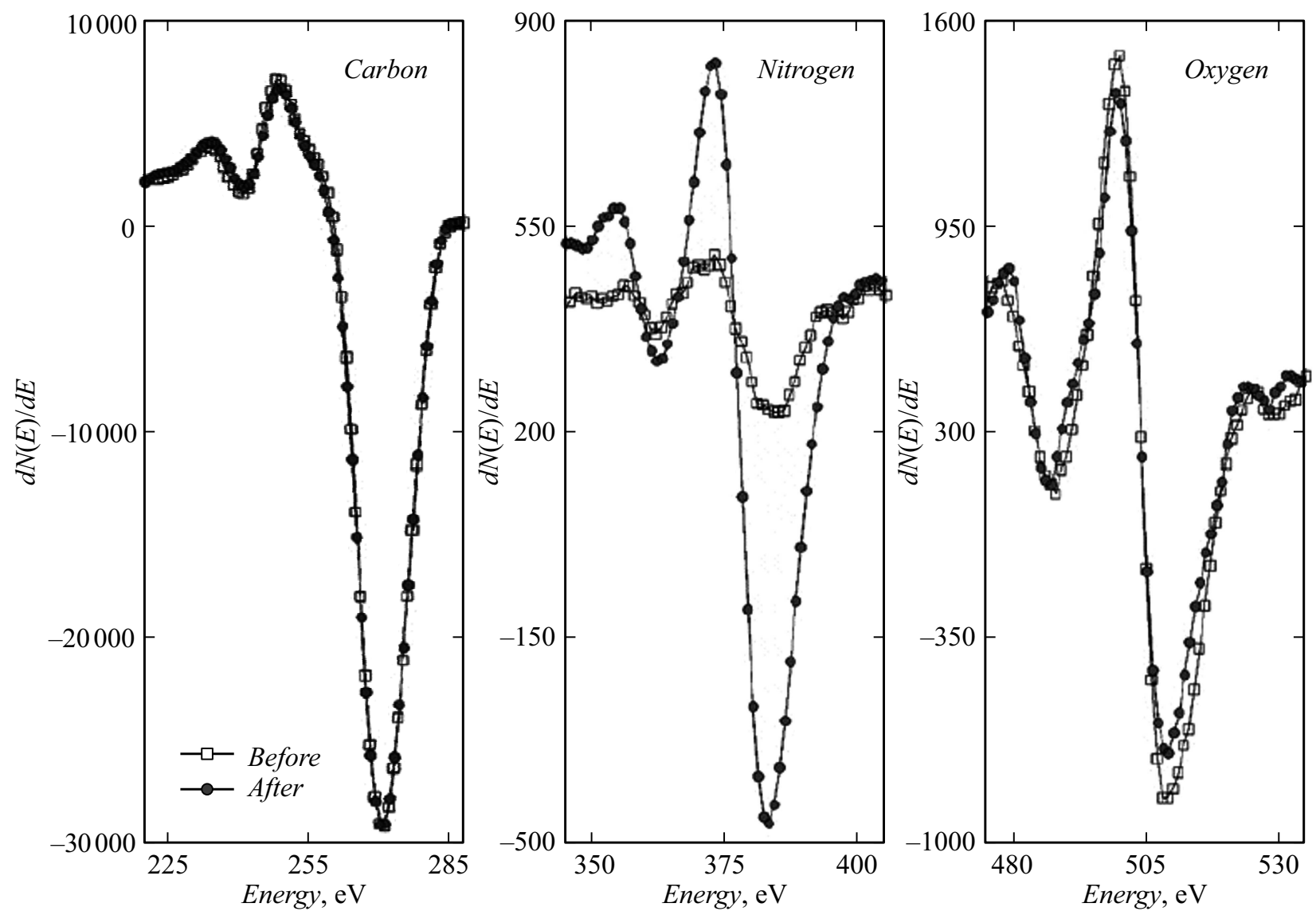

Рис. 1. Дифференциальные оже-спектры основных элементов в синтезированных углеродных нанотрубках. Квадраты - сразу после синтеза, кружки - после обработки в плазме аммиака.

для высокочастотной составляющей и $30 \mathrm{~W}$ для низкочастотной. Таким образом, азотсодержащие газы в процессе синтеза не использовались.

Синтезированные образцы исследовались методом оже-электронной спектроскопии на предмет содержания азота в нанотрубках, также измерялись их эмиссионные вольт-амперные характеристики. После этого часть образцов подвергалась обработке в плазме аммиака в течение $10 \mathrm{~min}$ при температуре $T=680^{\circ} \mathrm{C}$ в высокочастотном плазменном разряде аммиака мощностью $100 \mathrm{~W}$. При этом расход $\mathrm{NH}_{3}$ составлял $100 \mathrm{~cm}^{3} / \mathrm{min}$ при давлении 1.5 Torr. После обработки образцов в плазме измерения повторялись.

Дифференциальные оже-электронные спектры (ОЭС) для энергетических областей углерода, азота и кислорода приведены на рис. 1. Чувствительность ожеэлектронного спектрометра Jeol JAMP-9510F составляет 0.3 at.\% для азота при данных условиях съемки, содержание азота в синтезированных образцах не превышает 0.7 at.\%. После обработки в плазме азота интенсивность ОЭС-пика азота увеличилась более чем в 4 раза, а атомная концентрация азота возросла до 3.6 at.\%.

Также изменялись и вольт-амперные характеристики (рис. 2). До обработки в плазме последовательное сопротивление было равно $140 \pm 10 \mathrm{k} \Omega$, после обработки

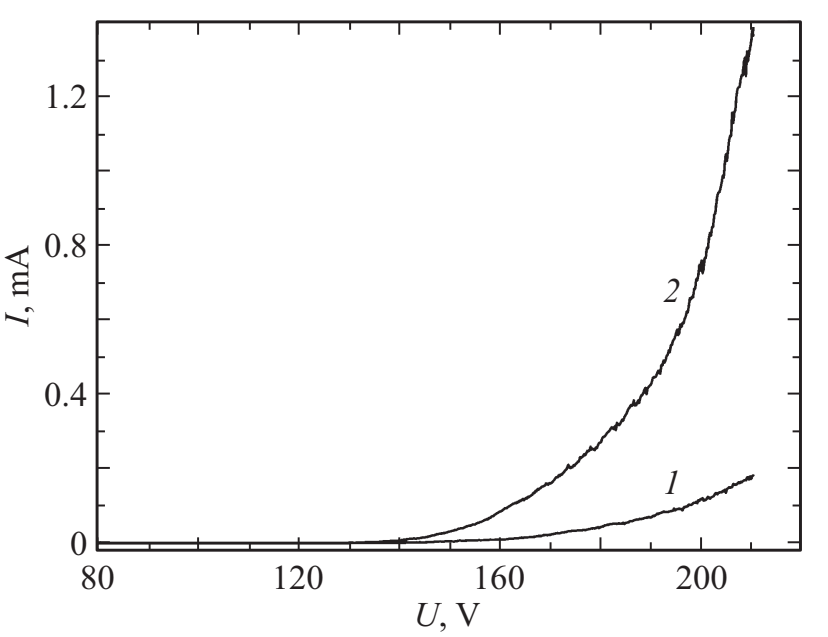

Рис. 2. Эмиссионные вольт-амперные характеристики массива УНТ. 1 - образцы сразу после синтеза, 2 - образцы после обработки в плазме аммиака.

в плазме сопротивление составило $23 \pm 8 \mathrm{k} \Omega$. Обработка в плазме привела и к незначительному уменьшению наклона вольт-амперной характеристики, построенной в координатах Фаулера-Нордгейма, что соответствует 


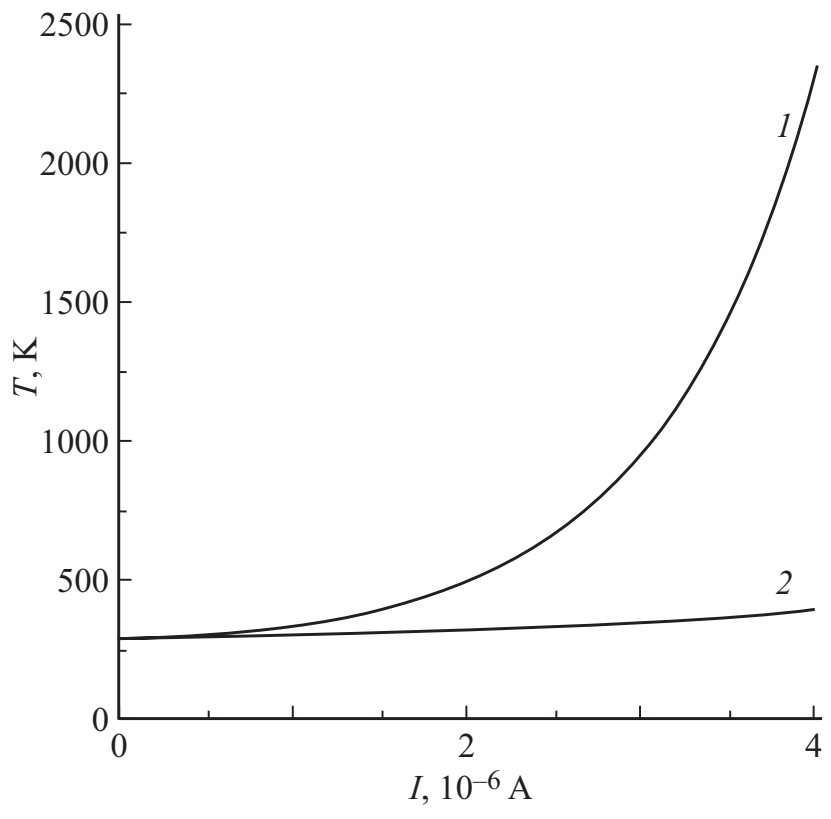

Рис. 3. Расчет зависимости температуры эмитирующего конца нанотрубки длиной $2.4 \mu \mathrm{m}$ от величины протекающего тока. 1 - образцы сразу после синтеза, 2 - образцы после обработки в плазме аммиака.

некоторому снижению работы выхода на величину около $10 \%$.

Снижение сопротивления в 6 раз привело к уменьшению разогрева образца и стабилизации эмиссии. Действительно, в образцах до плазменной обработки ток эмиссии уменьшался на величину около $20 \%$ за первые два часа работы. После плазменной обработки снижение тока не происходило даже после $20 \mathrm{~h}$ работы эмиттера при той же величине тока, что и у образцов сразу после синтеза. Для того чтобы оценить уменьшение температуры нанотрубок, которые участвовали в эмиссии, были выполнены расчеты по методике, изложенной в работе [4]. В зависимости от протекающего тока температура эмитирующего конца УНТ-образцов без обработки и с обработкой в плазме аммиака существенно различается. На рис. 3 приведен расчет зависимости температуры эмитирующего конца от величины протекающего тока для нанотрубки длиной $2.4 \mu \mathrm{m}$. Понижение температуры связано с уменьшением джоулева тепла, которое выделяется на нанотрубках.

Таким образом, в процессе обработки нанотрубок в плазме аммиака происходит их легирование. На это указывает уменьшение сопротивления, которое связано с тем, что азот в нанотрубках действует как донорная примесь [5]. Уменьшение сопротивления массива нанотрубок приводит к уменьшению количества тепла, которое выделяется в нанотрубках, при этом температура эмитирующего конца нанотрубок падает. Уменьшение разогрева нанотрубок приводит к стабилизации процесса эмиссии, так как повышенная температура является деструктивным фактором, который обусловливает деградацию.

\section{Финансирование работы}

Работа выполнена при поддержке Минобрнауки России (проект № 0004-2019-0003) с использованием УНУ КУТГИ ИНМЭ РАН.

\section{Конфликт интересов}

Авторы заявляют, что у них нет конфликта интересов.

\section{Список литературы}

[1] Bargaoui Y., Troudi M., Bondavalli P., Sghaier N. // Diamond Relat. Mater. 2018. V. 84. P. 62-65. DOI: 10.1016/j.diamond.2018.03.011

[2] Zhang Y., Tan Y., Wang L., Li B., Ke Y., Liao M., Xu N., Chen J., Deng S. // Vacuum. 2020. V. 172. P. 109071 (1-6). DOI: 10.1016/j.vacuum.2019.109071

[3] Parveen S., Kumar A., Husain S., Husain M. // Physica B. 2017. V. 505. P. 1-8. DOI: 10.1016/j.physb.2016.10.031

[4] Булярский С.В., Дудин А.А., Лакалин А.В., Орлов А.П., Павлов А.А., Рязанов Р.М., Шаманаев А.А. // ЖТФ. 2018. Т. 88. В. 6. С. 920-925. DOI: $10.21883 /$ JTF.2018.06.46026.2447 [Пер. версия: 10.1134/S1063784218060099].

[5] Doping of carbon nanotubes / Eds S. Bulyarskiy, A. Saurov. Ser. NanoScience and Technology. Cham: Springer International Publ., 2017. 187 p.

[6] Zhao Z., Gao C., Ma K., Lu Y. // Appl. Surf. Sci. 2020. V. 504. P. 144380 (1-6). DOI: 10.1016/j.apsusc.2019.144380

[7] Kvashnin D.G., Sorokin P.B., Brüning J.W., Chernozatonskii L.A. // Appl. Phys. Lett. 2013. V. 102. P. 183112. DOI: $10.1063 / 1.4804375$

[8] Chan K.T., Neaton J.B., Cohen M.L. // Phys. Rev. B. 2008. V. 77. P. 235430. DOI: 10.1103/PhysRevB.77.235430

[9] Maity A., Das S., Sen D., Chattopadhyay K.K. // Carbon. 2018. V. 127. P. 510-518. DOI: 10.1016/j.carbon.2017.11.018

[10] Nawn D., Banerjee D., Chattopadhyay K.K. // Diamond Relat. Mater. 2013. V. 34. P. 50-59. DOI: $10.1016 /$ j.diamond.2013.02.001

[11] Suzuki S., Bower C., Watanabe Y., Zhou O. // Appl. Phys. Lett. 2000. V. 76. P. 4007-4009. DOI: 10.1063/1.126849

[12] Kwon K.C., Choi K.S., Kim B.J., Lee J.-L., Kim S.Y. // J. Phys. Chem. C. 2012. V. 116. P. 26586-26591.

DOI: $10.1021 / \mathrm{jp} 3069927$

[13] Xu S.-F., Yuan G., Li C., Liu W.-H., Mimura H. // J. Phys. Chem. C. 2011. V. 115. P. 8928-8933.

DOI: $10.1021 / \mathrm{jp} 200885 \mathrm{~m}$

[14] Zhao G., Zhang Q., Zhang H., Yang G., Zhou O., Qin L.-C. // Appl. Phys. Lett. 2006. V. 89. P. 263113. DOI: $10.1063 / 1.2420796$

[15] Булярский С.В., Богданова Д.А., Кицюк Е.П., Лакалин А.В., Павлов А.А., Рязанов Р.М., Шаманаев А.А., Шаман Ю.П. // Письма в ЖТФ. 2018. Т. 44. В. 10. С. 5560. DOI: 10.21883/PJTF.2018.10.46099.17236 [Пер. версия: $10.1134 / \mathrm{S} 1063785018050164]$. 
[16] Bulyarskiy S.V., Dudin A.A., Lakalin A.V., Orlov A.P., Pavlov A.A., Ryazanov R.M., Shamanaev A.A. // Charact. Appl. Nanomater. 2019. V. 2. DOI: 10.24294/can.v2i2.567

[17] Сауров А.Н., Булярский С.В. // Микроэлектроника. 2017. T. 46. № 1. C. 3-13. DOI: 10.1134/S1063739717010103

[18] Usachov D., Vilkov O., Grüneis A., Haberer D., Fedorov A., Adamchuk V.K., Preobrajenski A.B., Dudin P., Barinov A., Oehzelt M., Laubschat C., Vyalikh D.V. // Nano Lett. 2011. V. 11. P. 5401-5407. DOI: $10.1021 / \mathrm{nl} 2031037$

[19] Arenal R., March K., Ewels C.P., Rocquefelte X., Kociak M., Loiseau A., Stéphan O. // Nano Lett. 2014. V. 14. P. 5509 5516. DOI: $10.1021 / \mathrm{n} 1501645 \mathrm{~g}$

[20] Zhang Z., Cho K. // Phys. Rev. B. 2007. V. 75. P. 075420. DOI: 10.1103/PhysRevB.75.075420 